\title{
Alterações histológicas em brânquias de tilápia nilotica Oreochromis niloticus causadas pelo cádmio
}

\author{
[Histological alterations in gills of Nile tilapia Oreochromis niloticus caused by cadmium] \\ S. Garcia-Santos, S.M. Monteiro, J. Carrola, A. Fontainhas-Fernandes* \\ Universidade de Trás-os-Montes e Alto Douro \\ Centro de Estudos Tecnológicos, do Ambiente e da Vida - CETAV \\ Apartado 1013 \\ 5000-911 Vila Real, Portugal
}

\begin{abstract}
RESUMO
Os efeitos histopatológicos do cádmio nas brânquias de tilápia Oreochromis niloticus foram estudados por microscopia óptica, usando $25 \mathrm{mgl}^{-1}$ de $\mathrm{CdCl}_{2}$ durante quatro dias, com o objetivo de identificar seus efeitos agudos na estrutura das brânquias. A morfologia geral das brânquias de $O$. niloticus é idêntica à de outros teleósteos, apresentando quatro pares de arcos branquiais com filamentos bem desenvolvidos. Situadas lateralmente, encontram-se as lamelas provenientes do eixo central dos filamentos. No epitélio filamentar foi possível identificar células de cloro, pavimentosas e mucosas. Os peixes expostos ao cádmio mostraram sinais de lesões epiteliais; edema intersticial, vasodilatação das lamelas, destacamento do epitélio lamelar e proliferação do epitélio filamentar. As alterações observadas também incluíram fusão nas lamelas como resultado de hiperplasia e hipertrofia epitelial, ruptura do sistema de células pilar, aneurismas e necroses.
\end{abstract}

Palavras-chave: tilápia, Oreochromis niloticus, cádmio, histopatologia, brânquias

\begin{abstract}
The histopathogical effects of cadmium on the gills of tilapia Oreochromis niloticus were studied by light microscopy, using $25 \mathrm{mgl}^{-1}$ of $\mathrm{CdCl}_{2}$ during four days to identified the effects of short-term exposure on gills structure. The general morphology of $\mathrm{O}$. niloticus gills is similar to the other teleostean fishes, showing four pairs of gills arches with well developed filaments. Bilaterally situated, secondary lamellae branches are found from the central axis of the filaments. The filamentar epithelium showed the chloride cells, the pavement cells and mucous cells. Fish exposed to cadmium showed signs of epithelial lesion, namely the interstitial edema, swollen of the lamellae, lifting and cellular proliferation of the filamentar epithelium. The changes of the gills also included lamellar fusion as a result of epithelial hyperplasia and hypertrophy, the breakdown of pillar cell system, and aneurisms with some ruptures and necrosis, especially in the filamentar epithelium.
\end{abstract}

Keywords: tilapia, Oreochromis niloticus, cadmium, histopathology, gills

\section{INTRODUÇ̃̃O}

A organização geral das brânquias de teleósteos baseia-se num sistema de subdivisões sucessivas, e o seu epitélio é constituído por diversos tipos celulares, em particular, por células pavimentosas de revestimento, células de cloro e mucosas (Monteiro et al., 2004). As brânquias são um órgão envolvido nas trocas gasosas, no balanço ácido-base e no transporte e excreção de compostos azotados (Perry, 1997). A sua multifuncionalidade, a vasta área de superfície

Recebido em 10 de Fevereiro de 2005

Aceito em 18 de janeiro de 2007

* Autor para correspondência (corresponding author)

Fontain@utad.pt 
que ocupa e a sua localização relativamente ao meio externo fazem das brânquias um órgão chave para a ação dos poluentes existentes no meio aquático. Nesse sentido, as alterações histológicas da brânquia são reconhecidas como um método rápido e válido para determinar os danos causados pela exposição a diferentes poluentes nos peixes (Arellano et al., 1999).

$\mathrm{O}$ cádmio $(\mathrm{Cd})$ é um metal pesado muito utilizado em estudos de toxicologia, devido ao aumento significativo da sua concentração no ambiente, resultante da crescente acumulação de resíduos industriais e domésticos (Wright e Welbourn, 1994; Goering et al., 1995). Adicionalmente, o seu caráter persistente e a sua conseqüente acumulação nos organismos conferem-lhe um significado ecológico importante (Jensen e Bro-Rasiriussen, 1992; Alazemi et al., 1996). Sabe-se que a presença do Cd em concentrações elevadas pode originar a desova prematura, um atraso no crescimento e o aumento da mortalidade em peixes (Beholt et al., 1976).

Os efeitos da exposição ao $\mathrm{Cd}$ têm sido investigados ao nível morfológico e bioquímico em diferentes espécies de peixes (Pratap e Wendelaar Bonga, 1993; Wong e Wong, 2000; Garcia-Santos et al., 2005). Os teores mais elevados em $\mathrm{Cd}$ foram detectados nos rins, fígado e nas brânquias (Cattani et al., 1996). A informação atual sobre alterações histológicas provocadas pelo $\mathrm{Cd}$ nas brânquias, tanto em condições agudas como crônicas, ainda é escassa (Thophon et al., 2003).

O objetivo deste trabalho foi identificar as principais alterações histológicas das brânquias de tilápia nilotica $O$. Niloticus causadas pela exposição ao cádmio durante um período de quatro dias.

\section{MATERIAL E MÉTODOS}

As tilápias foram fornecidas pelo Institut National de Recherche Agronomique (Rennes, França) e mantidas em condições de laboratório na Universidade de Trás-os--Montes e Alto Douro durante três gerações. A reprodução ocorreu em cativeiro em condições controladas e as pós-larvas foram recolhidas de fêmeas de $O$. niloticus 10 a 12 dias depois da fecundação em água doce, logo após a reabsorção do saco vitelino. Até o início do experimento com o cádmio, a manutenção dos alevinos foi efetuada em um sistema de água recirculada em aquários de 6001, com fluxo de água constante.
A água foi mantida a uma temperatura constante de $25 \pm 1^{\circ} \mathrm{C}$ e o fotoperíodo foi controlado durante $12 \mathrm{~h}$. Foi fornecida oxigenação suplementar em cada tanque para manter os níveis de oxigênio próximos da saturação. Os principais parâmetros de qualidade da água, teores de amônia, nitritos, nitratos e sólidos em suspensão, foram controlados periodicamente, sendo mantidos de acordo com os limites considerados satisfatórios para a espécie, mediante filtração biológica e mecânica (Fontaínhas-Fernandes, 1999).

Doze tilápias em idade adulta, com peso e tamanho médios de $47,2 \pm 2,4 \mathrm{~g}$ e $11,1 \pm 0,14 \mathrm{~cm}$, respectivamente, foram expostas em seis tanques de 1001 em água com $25 \mathrm{mgl}^{-1}$ de $\mathrm{CdCl}_{2}$ durante quatro dias, sendo a concentração de $\mathrm{Cd}$ mantida constante. Uma solução stock de $\mathrm{CdCl}_{2}$ foi adicionada a três tanques no início do experimento, com vista a alcançar a concentração pretendida. Os peixes do grupo-controle foram mantidos em outros tanques, em condições idênticas em água doce sem adição de Cd.

Os peixes foram ligeiramente anestesiados com monofenil-éter-etileno-glicol ${ }^{1}$, tendo sido recolhido $\mathrm{o}$ terceiro arco branquial do lado esquerdo $\mathrm{e}$ processado por rotina para estudos de microscopia óptica. O tecido branquial foi fixado em Bouin durante 24 horas, desidratado em concentrações crescentes de álcool e incluído em parafina líquida. Foram feitos cortes de $5 \mu \mathrm{m}$ em micrômetro rotativo $^{2}$ e corados em hematoxilina-eosina. As alterações induzidas pelo cádmio foram analisadas e fotografadas em microscópio óptico $600 \mathrm{~N}^{3}$.

\section{RESULTADOS}

A tilápia nilotica $O$. Niloticus possui quatro arcos branquiais, situados de cada lado da cavidade bucal. Cada arco branquial tem uma estrutura cartilaginosa e possui uma fileira dupla de filamentos branquiais achatados dorso-ventralmente. Esses filamentos subdividem-se em lamelas branquiais que se encontram dispostas perpendicularmente. Os filamentos branquiais possuem um epitélio estratificado, constituído por diversos tipos de células, entre os quais foi possível distinguir as células de cloro, mucosas e pavimentosas (Fig. 1).

O epitélio assenta-se sobre o seio venoso central e encontra-se segmentado por eixos vasculares que

\footnotetext{
${ }^{1}$ Merck - New Jersey, EUA

${ }^{2}$ Leica-RM 2135 - Heideberg, Alemanha

${ }^{3}$ Nikon Labophot - Portugal
} 


\section{Garcia-Santos et al.}

originam as lamelas. Essas estruturas representam projeções teciduais acima da superfície externa do epitélio filamentar. Desse modo, as lamelas são constituídas centralmente por um eixo vascular e por um epitélio composto por células pavimentosas de revestimento e indiferenciadas. Esse epitélio assenta-se na lâmina basal de células endoteliais modificadas (células pilar) que suportam e delimitam o compartimento sangüíneo lamelar.

As brânquias dos peixes mantidos em água doce sem adição de $\mathrm{Cd}$ (grupo-controle) apresentaram aspecto normal. Os peixes expostos ao poluente mostraram algumas alterações histológicas, proliferação do epitélio filamentar, vasodilatação do seio venoso central e da região basal do eixo vascular das lamelas e destacamento do epitélio

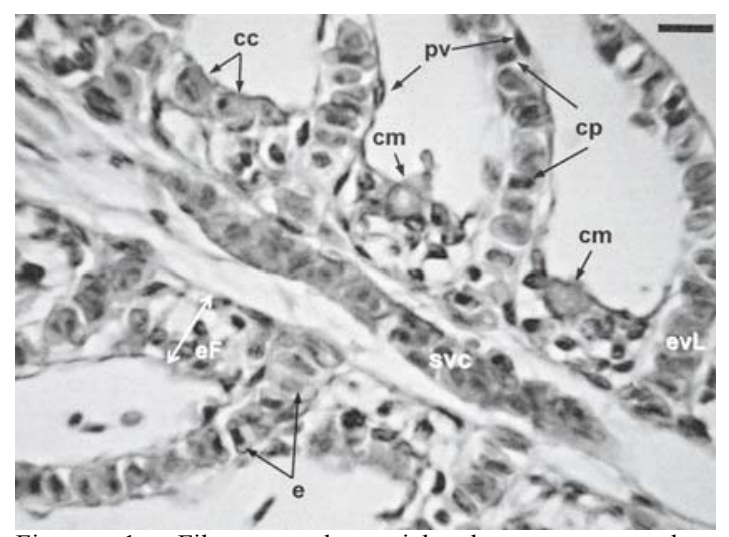

Figura 1. Filamento branquial do grupo-controle. $\mathrm{Cc}=$ células de cloro, $\mathrm{cm}=$ células mucosas, $\mathrm{cp}=$ células pilar, $\mathrm{e}=$ eritrócitos, $\mathrm{eF}=$ epitélio filamentar, $\mathrm{evL}=$ eixo vascular da lamela, $\mathrm{pv}=$ células pavimentosas, $\mathrm{svc}=$ seio venoso central. Microscopia óptica, HE. (Barra $=10 \mu \mathrm{m})$.

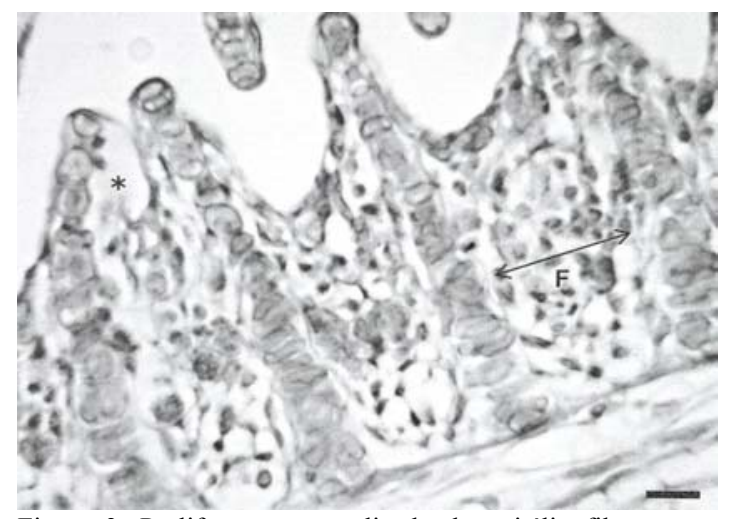

Figura 3. Proliferação generalizada do epitélio filamentar com fusão (F) quase total das lamelas branquiais. Edema intersticial (*). Microscopia óptica, HE. (Barra $=10 \mu \mathrm{m})$. lamelar associado a edema intersticial pronunciado (Fig. 2 e 3). A proliferação do epitélio filamentar estendeu-se a toda a área epitelial conduzindo à fusão quase completa das lamelas (Fig. 3). A necrose constituiu outro tipo de lesão observado, a qual foi mais acentuada na base do epitélio filamentar estendendo-se, por vezes, na sua totalidade (Fig. 4). Esse tipo de lesão caracterizouse pela condensação dos núcleos e ruptura das membranas celulares e resultou da ação direta do poluente. A vasodilatação marcada do eixo vascular das lamelas também foi observada, tendo por vezes conduzido à ruptura das células pilar (Fig. 5), com perda da sua capacidade de suporte. Esse fato pode ter conduzido ao aparecimento de aneurismas lamelares que estão representados na Fig. 6.

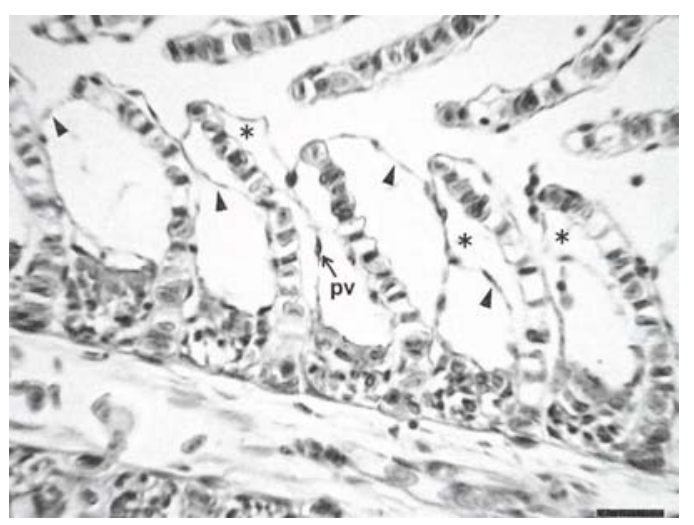

Figura 2. Destacamento do epitélio lamelar (cabeça de setas) e edema intersticial (*). Nota-se vasodilatação na base do eixo vascular das lamelas. $\mathrm{Pv}=$ célula pavimentosa. Microscopia óptica, HE. (Barra $=20 \mu \mathrm{m})$.

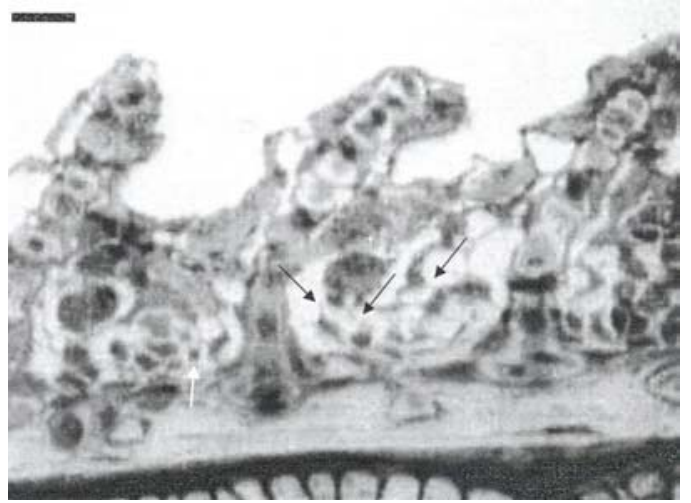

Figura 4. Núcleos picnóticos (setas brancas), ruptura de membranas celulares (setas pretas), característicos de necrose. Células basais com citoplasma translúcido, ausência de organelas citoplasmáticas. Necrose na base do epitélio filamentar. Microscopia óptica,HE. (Barra=10 $\mu \mathrm{m})$. 


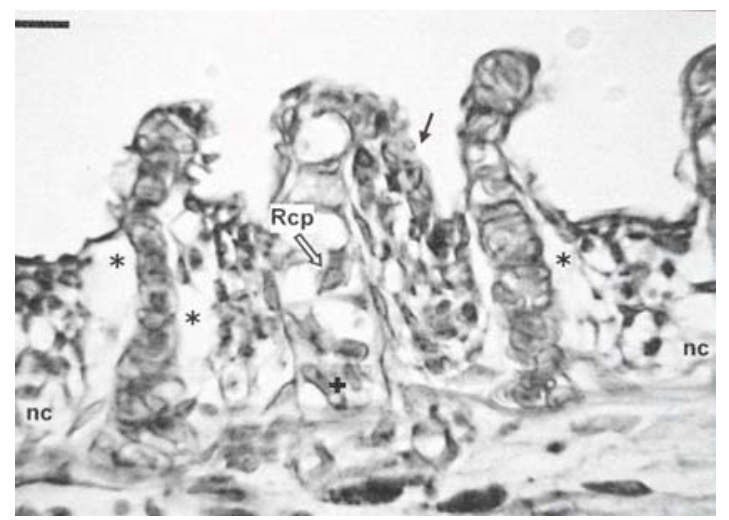

Figura 5. Ruptura de uma célula pilar (Rcp) associada a congestão vascular (+), edema justalamelar pronunciado (*), proliferação do epitélio filamentar (seta preta) e necrose (nc). Microscopia óptica, HE. (Barra $=10 \mu \mathrm{m})$.

\section{DISCUSSÃO}

O epitélio da brânquia é a principal superfície de contacto com o ambiente e constitui um importante alvo dos poluentes presentes na água, devido à sua extensa área superficial (Wong $\mathrm{e}$ Wong, 2000). Nesse sentido, a análise das alterações histológicas das brânquias dos teleósteos causadas pela exposição aos metais pesados tem merecido um interesse crescente em estudos de toxicologia (Pratap e Wendelaar Bonga, 1993; Thophon et al., 2003).

Segundo Mallatt (1985), uma das principais alterações estruturais das brânquias causadas pela exposição aos metais pesados consiste no aparecimento de edema nos epitélios lamelar e filamentar. No presente estudo, verificou-se essa lesão com maior incidência ao nível das lamelas, o que pode ter conduzido a um extenso destacamento epitelial observado. Thophon et al. (2003) referem-se à presença de edema acompanhado pelo destacamento do epitélio lamelar como sendo um primeiro sinal de patologia em peixes.

O espessamento do epitélio filamentar e lamelar também tem sido observado em estudos efectuados em peixes expostos a diferentes poluentes (Arellano et al., 2000). Esse aumento do epitélio pode ser devido à proliferação de células de cloro e de células indiferenciadas (Dang et al., 1999). Neste trabalho, a exposição ao cádmio induziu apenas a proliferação do epitélio filamentar, a qual conduziu, por vezes, à fusão parcial ou total das lamelas branquiais. Thophon et al. (2003) observaram resultados

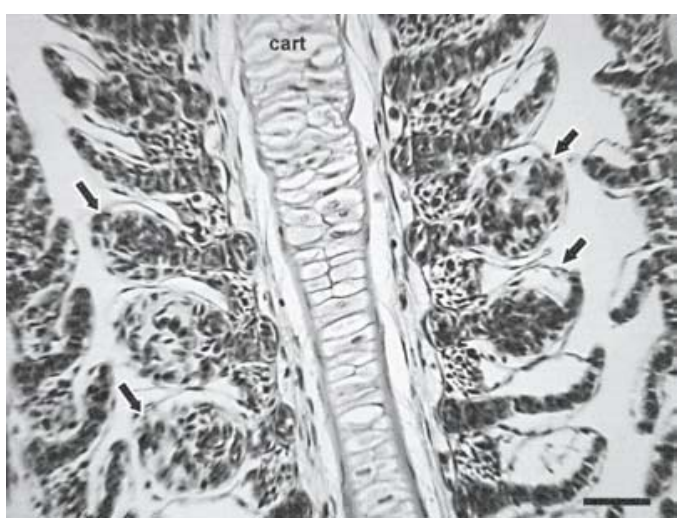

Figura 6. Vasodilatação do eixo vascular das lamelas com perda da capacidade de suporte das células pilar e formação de aneurismas (setas). Cart $=$ cartilagem. Microscopia óptica, HE. (Barra $=20 \mu \mathrm{m})$.

idênticos em Lates calcarifer submetido ao cádmio. Resultados similares foram obtidos em tilápia nilótica $O$. Niloticus exposta ao cobre por Monteiro (2001) e Monteiro et al (2005).

Outras lesões observadas foram o edema intersticial, o destacamento epitelial, a proliferação do epitélio filamentar e a fusão de lamelas. Essas alterações histológicas funcionam como mecanismos de defesa, porque diminuem a área de superfície vulnerável da brânquia e/ou aumentam a barreira de difusão ao poluente (Karlsson-Norrgren et al., 1985; Erkmen e Kolankaya, 2000). Essas respostas dificultam o acesso do poluente ao sangue prejudicando, contudo, a realização de trocas gasosas (McDonald e Wood, 1993). Por sua vez, as dificuldades respiratórias podem ser responsáveis pela indução da vasodilatação.

A vasodilatação do eixo vascular das lamelas conduziu, por vezes, à ruptura das células pilar com perda da sua capacidade de suporte, levando ao aparecimento dos aneurismas lamelares. Resultados similares foram observados por Thophon et al. (2003) em L. calcarifer também submetidos à exposição ao cádmio.

A necrose e a ruptura do epitélio branquial também foram observadas neste estudo. Tratamse de lesões que refletem o efeito direto dos poluentes (Temmink et al., 1983) e que ocorrem em condições de maior toxicidade (Abel et al., 1976). A exposição de tilápia nilótica $O$. Niloticus ao cobre também conduz ao aparecimento de necrose quando exposta a uma

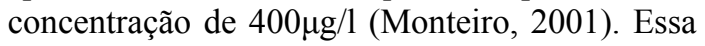


morte celular pode resultar da acumulação de cobre, que induz danificação celular e aumento da substituição celular e da regeneração epitelial (Pelgrom et al., 1995). A degeneração por necrose e apoptose das células do epitélio branquial, essencialmente, células de cloro e pavimentosas, também foi mencionada em estudos de natureza ultraestrutural realizados em teleósteos submetidos a diferentes poluentes (Pratap e Wendelaar Bonga, 1993; Mazon et al., 2002).

\section{CONCLUSÃo}

As alterações histológicas revelam que a crescente contaminação, causada pelos níveis de cádmio que afetam o ambiente aquático, conduz ao aparecimento de lesões nas brânquias de $O$. niloticus.

\section{REFERÊNCIAS BIBLIOGRÁFICAS}

ABEL, P.D. Toxic action of several lethal concentrations of an anionic detergent on the gills of the brown trout (Salmo trutta L.). J. Fish Biol., v.9, p.441-446, 1976.

ALAZEMI, B.M.; LEWIS, J.W.; ANDREWS, E.B. Gill damage in the freshwater fish Gnathonemus petersii (Family: Mormyridae) exposed to selected pollutants: an ultrastructural study. Environ. Technol., v.17, p.225-238, 1996.

ARELLANO, J.M.; BLASCO, J.; ORTIZ, J.B. et al. Accumulation and histopathological effects of copper in gills and liver of Senegales Sole, Solea senegalensis and toad fish, Halobatrachus didactylus. Ecotoxicol. Environ. Restor, v.3, p.22-28, 2000.

ARELLANO, J.M.; STORCH, V.; SARASQUETE, C. Histological changes and copper accumulation in liver and gills of the Senegales Sole, Solea senegalensis. Ecotoxicol. Environ. Safety, v.44, p.62-72, 1999.

BEHOLT, D.A.; LEONHARD, E.N.; CHRISTENSEN, G.M. et al. Toxic effects of cadmium on three generations of brook trout (Salvelinus fontinalis). Transact. Am. Fish Soc., v.105, p.550-560, 1976.

CATTANI, O.; SERRA, R.; ISANI, G. et al. Correlation between metallothionein and energy metabolism in sea bass, Dicentrachus labrax, exposed to cadmium. Comp. Bioch. Physiol., v.113, p.193-199, 1996.

DANG, Z.; LOCK, R.; FLIK, G. et al. Metallothionein response in gills of Oreochromis mossambicus exposed to copper in fresh water. Am. J. Physiol., v.277, p.320-331, 1999.

ERKMEN, B.; KOLANKAYA, D. Effects of water quality on epithelial morphology in the gill of Capoeta tinca living in two tributaries of Kizilirmak River, Turkey. Bull. Environ. Contam. Toxicol., v.64, p.418-425, 2000.

FONTAÍNHAS-FERNANDES, A.A. Contribuição para o estudo da tilápia Oreochromis niloticus L. (Pisces: Cichlidae). Aspectos nutricionais e aspectos fisiológicos ligados ao sexo e à salinidade do meio. 1999. 171f Tese (Doutorado) - Universidade de Trásos-Montes e Alto Douro, Vila Real.

GARCIA-SANTOS, S.; FONTAÍNHASFERNANDES, A.; WILSON, J.M. Cadmium tolerance in the Nile tilapia (Oreochromis niloticus) following acute exposure: Assessment of some ionoregulatory parameters. Environ. Toxicol., v.21, p.33-46, 2006.

GOERING, P.L.; WAALKES, M.P.; KLAASEN, C.D. Toxicology of cadmium. In: TOXICOLOGY OF METALS: Biochemical aspects. Berlin: Springer, 1995. p.189-214.

JENSEN, A.; BRO-RASIRIUSSEN, F. Environmental cadmium in Europe. Rev. Environ. Contam. Toxicol., v.125, p.101-181, 1992.

KARLSSON-NORRGREN, L.; RUNN, P.; HAUX, C. et al. Cadmium-induced changes in gill morphology of zebrafish, Brachydanio rerio (Hamilton- uchanan) and rainbow trout Salmo gairdneri Richardson. J. Fish Biol., v.27, p.8195, 1985.

MALLATT, J. Fish gill structural changes induced by toxicants and other irritants: a statistical review. Can. J. Fisheries Aquatic Sci., v.42, p.630-648, 1985.

MAZON, A.F.; CERQUEIRA, C.C.; FERNANDES, M.N. Gill cellular changes induced by copper exposure in the South American tropical freshwater fish Prochilodus scrofa. Environ. Res., v.88, p.52-63, 2002. 
MCDONALD, D.G.; WOOD, C.M. Branchial mechanisms of acclimation to metals in freshwater fish. In: FISH ECOPHYSIOLOGY. London: Chapman \& Hall, 1993. p.297-321.

MONTEIRO, S.M. Caracterização ultraestrutural do epitélio da brânquia de $\mathrm{O}$. niloticus: Efeitos da exposição ao cobre. 2001. 162f Tese (Mestrado) - Universidade de Trás-osMontes e Alto Douro, Vila Real.

MONTEIRO, S.M.; FONTAINHASFERNANDES, A.; SOUSA, M. Caracterização morfológica e ultrastrutural do epitélio branquial de peixes teleósteos. Rev. Port. Zootec., v.XI, p.13-36, 2004.

MONTEIRO, S.M.; MANCERA, J.M.; FONTAÍNHAS-FERNANDES, A. et al. Copper induced alterations of biochemical parameters in the gill and plasma of Oreochromis niloticus. Compar. Bioch. Physiol., v.141, p.375-383, 2005.

PELGROM, S.; LAMERS, L.; LOCK, R.; et al. Integrated physiological response of tilapia, Orechromis mossambicus, to sublethal copper exposure. Aquatic Toxicol., v.32, p.303-320, 1995.

PERRY, S.F. The chloride cell: structure and functions in the gills of freshwater fishes. Annual Rev. Physiol., v.59, p.325-347 1997.
PRATAP, H.B.; WENDELAAR BONGA, S.E. Effect of ambient and dietary cadmium on pavement cells, chloride cells, and sodium, potassium-ATPase activity in the gills of the freshwater teleost Oreochromis mossambicus at normal and high calcium levels in the ambient water. Aquatic Toxicol., v.26, p.133-150, 1993.

TEMMINK, J.; BOUWMEISTER, P.; DE JONG, P. et al. An ultrastructural study of chromate-induced hyperplasia in the gills of rainbow trout (Salmo gairdneri). Aquatic Toxicol., v.4, p.165-179, 1983.

THOPHON, S.; KRUATRACHUE, M.; UPATHAM, E.S. et al. Histopathological alterations of white seabass, Lates calcarifer, in acute and subchronic cadmium exposure. Environ. Pollut., v.121, p.307-320, 2003.

WONG, C.K.; WONG, M.H. Morphological and biochemical changes in the gills of Tilapia (Oreochromis mossambicus) to ambient cadmium exposure. Aquatic Toxicol., v.48, p.517-527, 2000.

WRIGHT, D.A.; WELBOURN, P.M. Cadmium in the aquatic environment: a review of ecological, physiological, and toxicological effects on biota. Environ. Rev., v.2, p.187-214, 1994. 